\section{The extended myocutaneous pectoralis major flap: A new tool for the successful coverage of the lower third in sternal dehiscence}

Sir,

Sternal dehiscence is one of the most common complications after median sternotomy, with an incidence of $0.2 \%-10 \% .^{[1-3]}$ The pectoralis major (PM) flap has achieved considerable success for its treatment, and many authors advocate its utilisation as first choice for sternal dehiscence reconstruction. ${ }^{[3]}$ However, its deficiency in providing coverage to the lower third of the sternum is a commonly stated fact. ${ }^{[2,3]}$

Many techniques have been proposed to provide coverage to the lower third, including combinations of locoregional flaps and even free flaps. ${ }^{[1-3]}$ In this article, we present a new technique aimed for the complete coverage of sternal defects; the extended myocutaneous PM (e-PMMC) flap associated with a distal Z-plasty.

The operation is scheduled once an appropriate resolution of the wound infection is achieved, after a period in which sequential debridements, antibiotics and negative pressure therapy are applied. The e-PMMC flap is designed by placing an expansion Z-plasty on the inferolateral portion of the sternal defect, forming two $60^{\circ}$ angles with the limit of the defect [Figures 1a and 2a]. The design descends $3 \mathrm{~cm}$ from the inferior margin of the wound, to compensate the shortening effect of its translocation.

Dissection starts by incising the Z-plasty, reaching the anterior rectus abdominis sheath. The flap is then elevated through the relatively avascular plane immediately deep to the PM muscle, reaching the anterior axillary line, and approximately the level of the clavicles. Inferiorly, the dissection plane passes from the deep surface of the PM to the deep surface of the anterior rectus fascia and continues caudally to the xiphoid process, elevating a small part of the anterior rectus sheath. The humeral insertion of the PM is transected with a harmonic scalpel through an independent incision. Next, 4 polyester-braided restraint stitches are attached to the contralateral costal periosteum at the medial limit of the flap.

This technique was performed in three patients, and in all cases, successful tension-free coverage of the sternal wound was achieved [Figures $1 \mathrm{~b}$ and $\mathrm{c}, 2 \mathrm{~b}$ and $\mathrm{c}$, including the lower third, without the apparition of any flap surgery-related complications during at least 12 -month follow-up. Surgery duration was lower than $60 \mathrm{~min}$.

No skin paddle necrosis or wound dehiscence occurred in the post-operative course.

The traditional surgical approach for the coverage of sternal defects which included the lower third implied the use of combinations of a PM flap for the coverage of the upper two-thirds, with another locoregional flap covering the lower third..$^{[1]}$ Notwithstanding, some authors start to advocate for the search of a flap that would permit the coverage of the whole sternal defect with the mobilisation of one single structure, thus decreasing the surgical aggression in a severely unstable

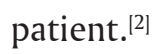

Our design allows the achievement of a stable coverage of the complete sternal defect, with a predictable flap width of about $10 \mathrm{~cm}$ while taking away all tension from the sternal area. Surgery duration is lower than $60 \mathrm{~min}$, being a scarcely traumatic procedure as it is performed through a relatively avascular plane, granting minimum blood loss. Furthermore, the utilisation of internal mammary arteries in the previous bypass surgery provides the e-PMMC flap with a delay phenomenon-like effect, reinforcing its vascularisation through the thoracoacromial axis, and therefore, its safety. ${ }^{[4]}$ 


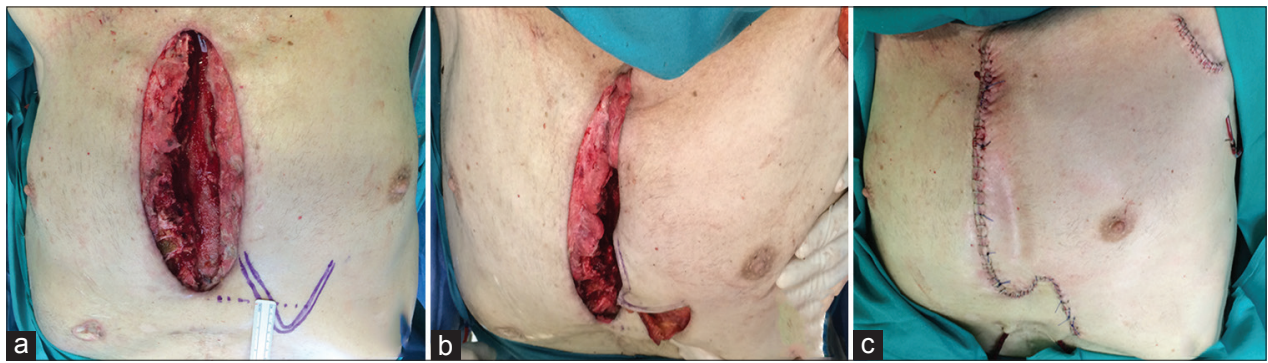

Figure 1: The Z-plasty descends $3 \mathrm{~cm}$ from the inferior margin of the wound. Pre-operative (a) intra-operative (b) and immediate post-operative (c) views of a 72-year-old man who developed a sternal dehiscence following a double coronary artery bypass and aortic valve replacement

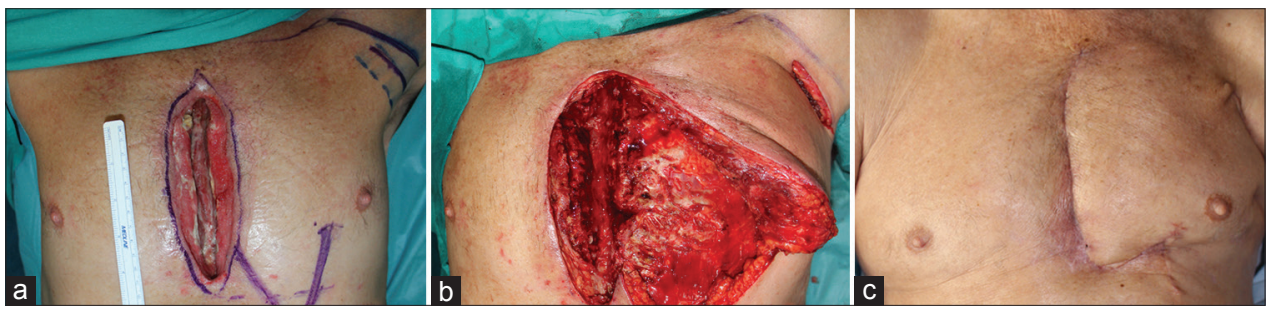

Figure 2: Pre-operative (a) intra-operative (b) and 6 months post-operative (c) views of a 69-year-old man who was treated with an extended myocutaneous pectoralis major for a sternal dehiscence developed 1 month after a quintuple coronary artery bypass

Taking into account that patients with sternal dehiscence tend to be afflicted with numerous chronical and severe conditions, ${ }^{[2]}$ the simplification of the coverage technique and reduction of its aggressiveness are determinant factors to advocate for the choice of this alternative.

\section{Financial support and sponsorship} Nil.

\section{Conflicts of interest}

There are no conflicts of interest.

\section{Eduardo Simón-Sanz, Enrique Salmerón-González, Eloisa Villaverde-Domenech, Alberto Pérez-García, Alberto Ruiz-Cases \\ Department of Plastic and Reconstructive Surgery, University and Polytechnic Hospital La Fe, Valencia, Comunidad Valenciana, Spain \\ Address for correspondence: \\ Dr. Enrique Salmerón-González, 4 Professor Lopez Piñero Avenue, Block 1, Appt. \#10, Fourth Floor, Valencia, Comunidad Valenciana, 46013, Spain. \\ E-mail: enrikes900@gmail.com}

\section{REFERENCES}

1. Lee $\mathrm{CH}$, Hsien JH, Tang YB, Chen HC. Reconstruction for sternal osteomyelitis at the lower third of sternum. J Plast Reconstr Aesthet Surg 2010;63:633-41.

2. Losanoff JE, Richman BW, Jones JW. Disruption and infection of median sternotomy: A comprehensive review. Eur J Cardiothorac Surg 2002;21:831-9.

3. Ascherman JA, Patel SM, Malhotra SM, Smith CR. Management of sternal wounds with bilateral pectoralis major myocutaneous advancement flaps in 114 consecutively treated patients: Refinements in technique and outcomes analysis. Plast Reconstr Surg 2004;114:676-83.

4. Dhar SC, Taylor GI. The delay phenomenon: The story unfolds. Plast Reconstr Surg 1999;104:2079-91.

This is an open access article distributed under the terms of the Creative Commons Attribution-NonCommercial-ShareAlike 3.0 License, which allows others to remix, tweak, and build upon the work non-commercially, as long as the author is credited and the new creations are licensed under the identical terms.

\begin{tabular}{|l|l|}
\hline \multicolumn{2}{|c|}{ Access this article online } \\
\hline Quick Response Code: & Website: \\
& www.ijps.org \\
\cline { 2 - 3 } & \\
\hline
\end{tabular}

How to cite this article: Simon-Sanz E, Salmerón-González E, Villaverde-Domenech E, Pérez-GarcíaA, Ruiz-Cases A. The extended myocutaneous pectoralis major flap: A new tool for the successful coverage of the lower third in sternal dehiscence. Indian J Plast Surg 2016;49:422-3. 